\title{
OS DIALETOS E OS JOVENS
}

Makoto Kuno

Hoje falarei sobre a essência da língua japonesa falada no Japão. É bem conhecido entre os japoneses que existem dialetos em várias partes do Japão, mas como a palavra dialeto pode ter significados diferentes em português e em japonês, primeiro explicarei o termo.

Eu conversava com um dos estudantes da USP e ele disse que no Brasil não havia dialetos. Fiquei surpreso ao ouvir isso. Pois ouvira dizer que no Brasil também havia diferença lingüística conforme a região; por exemplo, a pronúncia é diferente entre São Paulo e Rio; em Santos usa-se "tu" para a segunda pessoa; no Norte colocase "não" após o verbo. Além disso, na biblioteca da FFLCH há um Atlas Lingüístico, que não engloba todo o Brasil, mas mostra que muitas palavras diferem conforme a região. Por exemplo, há localidades onde "rabo-de-boi" e "xixi-de-boi" significam "arco-íris" Tal diferença lingüística regional é chamada de dialeto.

A língua está em constante transformação, assim a língua moderna com o tempo vai se tornando língua clássica. Porém, a mudança não é igual em todos os lugares. Uma palavra usada numa região é substituída por outra, vinda de outra região, ou então sofre uma mudança peculiar de pronúncia ou significado, originando pequenas

1. Professor Doutor da Faculdade de Educação da Kôchi University, Japão. Tradução da palestra "Wakamono to hôgen", proferida na ocasião do XVII Encontro Nacional de Professores Universitários de Língua, Literatura e Cultura Japonesa, na USP, em 2006. 
diferenças regionais. Algumas palavras e expressões são usadas temporariamente como modismos, outras se tornam permanentes.

A não ser que haja uma condição especial, a diferença lingüística é pequena entre regiões próximas, e maior entre localidades distantes, chegando a ponto de os falantes não se entenderem. Assim são formadas diferentes línguas, mas não existe regra para se definir quanta diferença seria necessária para serem consideradas duas línguas ou dois dialetos.

Entre o norte e o sul do Japão, há uma diferença tão grande a ponto de os dialetos serem incomunicáveis, mas todos são considerados dialetos da língua japonesa. Português e espanhol são considerados duas línguas distintas, apesar de seus falantes poderem se compreender mesmo sem ter estudado a outra língua. Similarmente norueguês, sueco e dinamarquês também são próximas, mas consideradas línguas distintas. Basicamente a diferença entre língua e dialeto não é determinada pela lingüística, e são consideradas línguas distintas levando em consideração os fatores históricos como política e cultura.

Há casos em que apesar de ser uma só língua da mesma região, o modo de usá-la varia conforme a classe social ou o grupo. Por exemplo, existem nomes de vento que só os pescadores conhecem, nomes de ferramentas de marceneiros que os outros desconhecem; creio que este fenômeno ocorre em qualquer país. Não sei quanto ao Brasil, mas no Japão notam-se muitos pontos em comum entre o falar da polícia e do yakuza. Se não fosse assim, seria inconveniente para ambos.

Segundo um sociolingüista, na Inglaterra, muitas vezes pelo falar de alguém é possível saber onde ele mora, em que trabalha e até que jornal lê. Além disso, mesmo vivendo na mesma cidade, as mulheres têm a tendência de falar inglês mais corretamente que os homens. Assim, podem-se chamar de dialetos as diferentes línguas faladas, conforme o grupo social a que se pertence, na mesma região geográfica.

Hoje falarei sobre a diferença geográfica da língua japonesa.

Como disse no início, em qualquer lugar do Japão existe um dialeto local. Os habitantes do lugar conversam em dialeto.

Antigamente, mesmo estudando a língua pátria (kokugo), língua comum, na escola, usava-se o dialeto na vida cotidiana. Havia até pessoas que não conseguiam falar a língua comum, mas a geração jovem passou a usar de forma distinta e com habilidade a língua comum e o dialeto. Usa-se muito a língua comum em ocasiões formais e com desconhecidos.

Entretanto, essa língua comum tem influência do dialeto local, seja em maior ou menor intensidade. Além disso, freqüentemente ocorrem mal-entendidos por não se perceber a diferença entre o dialeto e a língua comum.

Em outras palavras, todas as línguas faladas no Japão são japonês, mas pode-se dizer que todas são dialetos.

$\mathrm{O}$ japonês que menos gera mal-entendido é a língua escrita. $O$ texto escrito raramente reflete a diferença de pronúncia regional e é difícil que contenham expressões usadas apenas na língua falada. 
Hoje, até agora eu não usei a palavra "língua padrão" O motivo é que penso que ainda não existe um padrão na língua falada do japonês. A língua padrão deve ser aceita por todos, como sendo a mais correta e bela. Entretanto, essa língua não existe.

Por outro lado, a língua escrita no Japão veio sendo desenvolvida ao longo da história. Não se escreve muito em dialeto.

Não me interpretem mal, eu estudo os dialetos e não penso que os dialetos não sejam bonitos nem que sejam incorretos. Os dialetos concentram-se na língua falada. Vendo a língua japonesa em sua totalidade, penso que a língua escrita se constitui uma língua padrão.

Então como será a língua japonesa usada como base do ensino de língua pátria $\mathrm{e}$ língua estrangeira? Como disse agora, a língua escrita tem certo padrão. Como língua falada, o dialeto de Tóquio e de suas imediações serve como base e cumpre o papel de língua padrão.

É verdade, mas em Tóquio também há dialeto. Há pessoas nascidas e criadas em Tóquio que dizem "eu falo a língua padrão e não tenho dialeto", o que é um engano. Como disse antes, em toda parte do Japão há o dialeto local e Tóquio não é exceção. Apenas pode-se dizer que o dialeto de Tóquio tem forte aspecto padrão.

Então, vejamos rapidamente os dialetos do Japão.

A língua japonesa pode ser dividida amplamente em dialetos da ilha principal e dialeto Ryûkyû. A população falante do dialeto Ryûkyû é pequena, comparada à população total do país, mas é muito importante em termos lingüísticos.

A diferença entre os dialetos do leste e os do oeste, Kyûshû e Ryûkyûu, é se o verbo na negativa usa "nai" ou "n" E o uso de "iru" ou "oru" para a existência de pessoas e animais.

Em relação ao danteino jodôshi (auxiliar verbal de asserção), o dialeto do leste usa "da" e o do oeste e o de Kyûshû, "ja, ya"

Quanto ao aspecto verbal, o dialeto do leste usa " teiru", enquanto os do oeste e de Kyûshû diferenciam entre " yoru" e " toru"

Hoje, darei exemplos do dialeto de Tsugaru, região oeste da Província de Aomori, um dos dialetos da região leste. E como exemplo de dialeto da região oeste, tratarei do dialeto de Kôchi, onde moro atualmente.

$\mathrm{O}$ dialeto Tsugaru é conhecido como zûzûben. Zûzûben porque não há distinção entre / $/ \mathrm{i} /$ e /su/, /dzi/ e /zu/; por exemplo "sushi", "susu" (fuligem) e "shishi" (leão) ficam com a mesma pronúncia. "chichi" (seio), "tsutsu" (cilindro) e "tsuchi" (terra) também ficam iguais. "kaji" (incêndio) e "kazu" (quantidade) também são iguais.

A pronúncia difere levemente conforme a região e o intermediário entre $s u$ e shi é chamado vogal central. No sul da região nordeste, $/[\mathrm{d} /, / \mathrm{dzu} / \mathrm{e} / \mathrm{tj} \mathrm{u} /$ ficam iguais, então "jîsan" (velho) e "jûsan" (treze) também. Para habitantes de outras regiões, soam como "zûsan"

Quando pesquisei sobre o dialeto de Tsugaru, verifiquei as pronúncias de "chiji" (governador), "chizu" (mapa) e "Tsuji" (sobrenome japonês) e eram todas iguais. 
A sílaba da língua japonesa é chamada mora ( $h a k u$ ), que é uma unidade constituída por uma consoante seguida de uma vogal, mas hatsuon (nasal silábico), sokuon (som ejectivo) e chôon (vogal longa) também constituem uma mora. Isto fica claro quando contamos as sílabas em poemas tanka e haikai.

Entretanto, no dialeto de Tsugaru, praticamente não há hatsuon, sokuon e chôon, ou estes são muito curtos. Além disso, existe uma nasal antes de $/ \mathrm{b} /, / \mathrm{d} /, / \mathrm{g} /$ entre duas vogais. Essa nasal não é tão longa para constituir uma mora. Por isso "kuda" (tubo) e "kunda" (montou) têm a mesma pronúncia, assim como "karada" (corpo) e "karanda" (enroscou). O pretérito do verbo "kumu" (montar) na língua comum naturalmente é "kunda", mas o problema é como considerar neste dialeto. Igualmente o pretérito de "toru" (pegar) tem sokuon tâo curto que não se consegue distinguir se é "tota" ou "totta" Também não se consegue diferenciar "koban" (antiga moeda japonesa) e "kôban" (posto policial).

Há também o fenômeno em que $/ \mathrm{k} /$ entre vogais se torna $/ \mathrm{g} / \mathrm{e} / \mathrm{t} /$ muda para $/ \mathrm{d} /$. "sakeru" (evitar) fica "sageru" (abaixar), sendo /ge/ uma nasal velarizada. "Mato" (alvo) é pronunciado /mado/, sendo que /do/ de "mado" (janela) é pronunciado como nasal anterior.

Como não há distinção clara entre as vogais $/ \mathrm{i} / \mathrm{e} / \mathrm{e} /$, as pessoas de Ibaraki dizem /Ebaragi/, com a intenção de dizer /Ibaraki/. Ao ouvirem isto, os habitantes de outras regiões dizem/Ibaragi/, o que é um erro.

É natural que pessoas de outras localidades não compreendam um dialeto como o de Tsugaru. Por isso, desde antigamente estimulou-se o ensino no sentido de evitar o dialeto e usar a língua comum. A geração jovem já tem a fala mais próxima da língua comum. As pronúncias que mencionei estão sendo perdidas e apenas os idosos as usam. Eu disse geração jovem, mas mesmo as pessoas nas faixas de 60 e 70 anos também estão muito próximas da língua comum. Nas faixas de 30 e 40 anos, não deve existir alguém que não consiga distinguir $/ \mathrm{f} / \mathrm{e} / \mathrm{su} / \mathrm{e}$ "karada" é pronunciado com três moras e "karanda" com quatro. A partícula que expressa causa ou motivo no dialeto de Tsugaru é "ha"de", mas se tornou "hande" entre as pessoas abaixo dos 50 anos.

Agora falarei sobre a fusão de vogais seguidas. No dialeto do Nordeste ocorrem muitas fusões de vogais.

Mesmo entre os dialetos de Kantô, há muitos em que "akai" (vermelho) se torna akê, "shiroi" (branco) em shirê e "warui" (mau) em warî. Ocorrem muitos fenômenos semelhantes em dialetos das regiões Tôkai, Chûgoku e Kyûshû. Pode-se afirmar que os dialetos com fusão de vogais seguidas sejam a maioria, com a exceção da região Kinki.

As vogais seguidas não aparecem apenas em keiyôsh $i^{2}$, mas também em pretérito de verbo e em meishi (substantivos), mas hoje não mencionarei esses casos.

2. Associado muitas vezes ao adjetivo, por tratar-se de classe de palavra formada por vocábulos que expressam qualidade ou sentimento, mas constitui predicado, assim como os verbos. 
Quando /ai/ se transforma em /ê/, não é que surge uma vogal nova até então inexistente, mas nos dialetos do Nordeste e Tôkai, transforma-se em /e/ com a boca bem aberta como no português, ou como a vogal de map do inglês, tornando-se uma nova vogal.

A vogal /e/ dos dialetos do Nordeste é mais estreita (a posição da língua é alta) que na língua comum, soando como /i/. No caso de fusão de /ai/, fica igual à língua comum ou levemente ampla (a posição da língua é baixa), originando uma nova vogal.

No dialeto de Tsugaru, "akai" (vermelho) é /age /, sendo /e/ mais amplo que /ge/ de /tage/ ("take" = bambu).

Pode-se até afirmar que no dialeto de Tsugaru não há flexão de keiyôshi. Todas as terminações se ligam à forma terminativa das flexões shûshikei.

Os verbos que na língua comum terminam em /u/tomam-se /ru/. Apenas " $k u u$ " é exceção, mas sua flexão é diferente da língua comum. O verbo auxiliar " teshimau" também fica como " temaru"

Além disso, há algumas peculiaridades como a existência do auxiliar verbal (jodôshi) "saru" para indicar espontaneidade jihatsu, expresso na língua comum por "reru / rareru" e expressão de possibilidade por " ni ii" (pronuncia-se /e/).

Quanto à partícula, usa-se muito "be" para indicar intenção, indução e suposição, e "sa" para indicar direção e objeto.

Como disse, entre os "jovens", tais características fonéticas diminuíram, aproximando-se da língua comum; mas como explicarei sobre o dialeto de Kôchi, se considerarmos jovens aqueles que não apresentam a pronúncia do dialeto tradicional, e os idosos, os que têm pronúncia próxima da língua comum, é dificílimo definir a partir de quantos anos se é idoso e a partir de quanto anos se é jovem. Isto é porque nos dialetos atuais a diferença de faixa etária e diferença individual têm aumentado.

Vejamos agora um diálogo em dialeto de Tsugaru, encontrado na Internet. Creio que são jovens quem escrevem neste site. Acho que os senhores conseguirão entender um pouco, já que é muito semelhante à língua comum, comparada ao dialeto tradicional de Tsugaru.

Agora vejamos o dialeto de Kôchi.

O dialeto de Kôchi tem acento do tipo de Quioto e Osaka. Diferentemente do dialeto de Tsugaru, hatsuon e chôon tem a duração de uma mora e podem corresponder ao pico da acentuação tonal. $\mathrm{Na}$ acentuação tonal de Tóquio, o pico não pode vir em hatsuon nem chôon.

Historicamente é considerado como dialeto que conserva a acentuação tonal antiga de Quioto, mas nas gerações abaixo dos 50 anos, o sistema de acentuação tonal tem se modificado como no dialeto de Kinki. Na geração jovem, é crescente o número de pessoas que conseguem usar distintamente a acentuação da língua comum e a do dialeto. 
Um pouco semelhante ao dialeto de Tsugaru, /d/ e /g/ são precedidas por nasal anterior. Porém o mesmo não ocorre com $/ \mathrm{b} /$. Hatsuon tem a duração de uma mora e a nasal anterior não se mantém por muito tempo, por isso "karada" (corpo) e "karanda" (enroscou), "kago" (cesta) e "kango" (enfermagem) têm durações distintas.

$\mathrm{O}$ dialeto de Kôchi é conhecido por possuir distinção entre quatro sílabas (yotsugana) $/ \mathrm{zi} / \mathrm{e} / \mathrm{dzi} /, / \mathrm{zu} / \mathrm{e} / \mathrm{dzu} /$. Há cerca de vinte anos, pesquisei em duas cidades sobre o número de habitantes que conservavam tal distinção, mas já naquela época, crescia o número de pessoas abaixo de 60 anos que não as conseguiam distinguir claramente.

Acredita-se que em Quioto a distinção de quatro sílabas existira até o século XVII, mas desaparecera no final do mesmo século. Na língua comum distinguem-se / $\mathrm{zi} / \mathrm{e} / \mathrm{zu} /, \mathrm{mas} / \mathrm{zi} / \mathrm{e} / \mathrm{dzi} /, / \mathrm{zu} / \mathrm{e} / \mathrm{dzu} /$ são usados apenas na escrita.

No dialeto de Tsugaru, /zi/ e /dzi/, /zu/ e /dzu/ têm a mesma pronúncia, daí ser chamado de dialeto de uma sílaba (hitotsuga hôgen).

No oeste do Japão, usa-se o shieki (causativo) "su / sasu" No dialeto de Kôchi ocorre o mesmo. Além disso, em todo o país existe uma tendência de os ichidan dôshi $i^{3}$ transformarem-se em godan dôshi ${ }^{4}$, mas entre os jovens de Kôchi a tendência é mais acentuada no auxiliar verbal de causativo (shieki) e as formas de negação (como deran) e de intenção (dero) estão gradualmente deixando de ser usadas.

Sagyô ionbin é um fenômeno em que o pretérito e a forma que acompanha "te" de verbo terminado em "su", ao invés de " $\sim$ shita" $e$ " shite" passam para " ita" $e$ " ite" Em Quioto, isso ocorre também nas peças do teatro Kyôgen e acredita-se que era freqüente na Idade Média. Isso se conserva em Kôchi. A geração jovem de Kôchi usa muito a tal forma, no uso de causativo.

Já ouviram a expressão "ranuki kotoba" (palavras com omissão de ra)? Os ichidan dôshi (cf. nota 3), quando são acompanhados de auxiliares verbais de possibilidade "reru / rareru", passam para "rareru", como "okirareru" e "ukerareru", porém as formas com omissão de ra, ou seja, "okireru" e "ukereru" passaram a ser muito usadas e consideradas representantes da linguagem dos jovens. Mesmo nos editores de texto, ao se digitar "mireru", aparece a indicação "com omissão de $r a$ " $\mathrm{Na}$ verdade, este fenômeno surgiu há muito tempo conforme a região e em Kôchi até os idosos usam normalmente o "ranuki" Sentem que apenas "mireru" é insuficiente e chegam até a dizer "mirereru" "kaerereru" "kaesereru" Porém, como em todo o país, a geração jovem passou a usar sem ra, e, portanto, a forma "mirereru" está caindo em desuso, mantendo-se apenas "mireru"

Há pouco, eu expliquei que nos dialetos da região oeste e de Kyûshû, existe uma separação entre os tipos de auxiliares verbais yoru e toru. Em Kôchi, usam-se yû como tipo yoru e chû como tipo toru.

3. Verbos regulares II, que flexionam apenas no ru final, como taberu "comer", miru "ver";

4. Verbos regulares I, que flexionam nas cinco vogais, como kaku "escrever" (kaka, kaki, kaku, kaku, kake, kako). 
Em geral, yoru expressa a continuação e andamento da ação e toru, a permanência do resultado da ação. "Nomiyû " é a situação enquanto bebe. "Nonjû "é a situação após beber. Em todo o oeste do Japão, a diferença entre yoru e toru está tornando-se vaga. Prevê-se que yoru cairá em desuso e apenas toru permanecerá. $\mathrm{O}$ motivo é que, em alguns dialetos, praticamente não há yoru, restando apenas toru.

A partícula que indica causa / motivo é $k \hat{\imath}$, que tem diversas formas entre as regiões de Chûgoku, Shikoku e Kyûshû. Além disso, o auxiliar de afirmação ja está se modificando para ya, mas na região de Chûgoku, ja ainda domina; ya é mais fraco, mas em Kôchi as pessoas da faixa dos 20 anos praticamente usam ya. Porém, alguns homens na faixa dos 30 anos às vezes usam $j a$.

Segundo uma pesquisa sobre a gramática da língua falada, realizada pelo Ministério da Educação há quase cem anos, a Província de Gifu constava como região onde se usava ja. "Ja" era tão usado que até os habitantes de Gifu chamavam seu dialeto de "língua do ja de Mino", mas atualmente apenas homens acima da faixa de 80 anos o usam um pouco e praticamente foi substituído por " $y a$ " Vários devem ser os fatores que interferiram, mas pode-se concluir que se levou quase um século para que "ja" se transformasse em " $y a$ "

O que se ouve freqüentemente no dialeto de Kôchi além de $/$ chî/ e $/ k \hat{i} /$, é /ga/. Ele tem um significado semelhante à partícula nominalizadora (juntaijoshi) "no", mas não é partícula de caso (kakujoshi). Usa-se como "to" de Kyûshû.

A partícula final (shûjoshi) tem a função de expressar a emoção do falante e definir o significado de toda a frase, e por isso mesmo, existem várias formas em todo o país, sendo muito difícil levantar que nuance representa em quais situações. Em Kôchi, há muitas partículas finais (shûjoshi) como /zel, /zeyo/, /zonel, /chiyal, /neyal, $\mid \mathrm{kae} /$ e $/ y \mathrm{a} /$, mas seu levantamento e análise não estão avançados. Não está claro o quanto e com que significado os jovens usam, mas como há coisas que só o dialeto consegue expressar, não deve ser fácil substituí-lo pela língua comum. Certamente, o significado e o uso no dialeto devem ir-se modificando.

A propósito, há um material de levantamento sobre o quanto diminuiu o uso de nasal anterior por geração desde os 80 anos até abaixo dos 30 . Quatro pesquisadores transcreveram em símbolos fonéticos a fala de 75 pessoas. A proporção de nasal nos itens levantados foi apresentada em forma de gráfico.

Há uma diferença de diminuição de nasais em $\mathrm{d}$ e g. Também se constata tal diferença entre homens e mulheres. Pelo gráfico de proporção de nasais por faixa etária, percebe-se uma diminuição no total, mas nota-se uma grande diferença individual dentro da mesma geração.

A proporção de d nasalizado é alta nas faixas de 80 e 70 anos, mas quando começa a diminuir, a perda se acelera.

A proporção de nasais no g não é tão alta como d nas faixas de 80 e 70 anos, mas diminui gradativamente até a faixa dos 40 anos.

Abaixo dos 30 anos, não se constatam nasais, mas será que se pode dizer que é jovem ou idoso pela ocorrência de nasais? Há idosos sem muitas nasais, mas há pesso- 
as relativamente jovens com muitas nasais. Creio que essa diferença individual é uma característica do dialeto atual. Quem mora com os avós tem maior probabilidade de herdar o dialeto, enquanto quem não conversa muito com idosos só conhece o dialeto da geração jovem.

De qualquer modo, por mais que todo mundo no Japão consiga usar habilmente a língua comum, não se pode crer que os dialetos desaparecerão. Devem surgir novos dialetos e eles continuarão a ser usados sem serem percebidos como tais.

Até agora, acreditava-se que os idosos usavam muito os dialetos e os jovens, a língua comum, mas é preciso saber que o que é lingüisticamente antiquado não coincide tanto com a idade elevada.

Em todo lugar do Japão existe um dialeto local. Há muitas diferenças em relação ao japonês ensinado como língua estrangeira, mas conforme a maneira com que se encaram os dialetos, a linguagem dos jovens e os modismos, a língua japonesa parecerá mais interessante e divertida. Quando forem ao Japão, por favor, apreciem a língua local.

(Tradução de Kanami Hirai) 